\section{Chemistry publisher in move from print journals}

The American Chemical Society (ACS) is taking steps to turn most of its academic journals into online-only publications.

According to a letter seen by Nature - sent to ACS associate editors by Susan King, senior vice-president of ACS Publications in Washington DC - the move has been prompted by the "accelerated decline in demand for print subscriptions and the diminishing financial return from the print format". King foresees a "move beyond print to an electronic-only scientific publishing environment".

To save money, most ACS journals will, from July, begin printing two pages of reduced text sideways on each page. At the same time, subscribers will be offered incentives to switch to online-only access. In 2010, ACS members will no longer be able to buy print subscriptions of journals. For a longer version of this story, see http://tinyurl.com/llae53

\section{Researchers urge action on medical-isotope shortage}

US and Canadian medical researchers last week intensified their calls to tackle a worldwide shortage of radioisotopes for medical imaging.

Sudden dips in isotope supply occurred regularly in 2007 and 2008 as elderly reactors were shut down for repairs. The issue flared up again this year after an unscheduled 14 May shutdown of a large 52-year-old nuclear-isotope-production facility in Chalk River, Ontario, revealed a heavy water leak that has kept the facility closed. The Ontario plant and a reactor in Petten, the Netherlands, itself set to close in July for a month's maintenance, produce the majority of the world's medical isotope supply.

On 19 June, Canada's natural resources

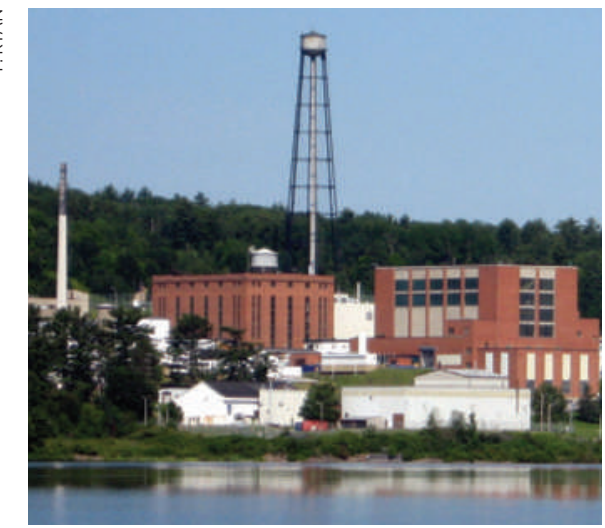

Safety issues have plagued the National Research Universal reactor at Chalk River Laboratories.

\title{
More financial woes for climate satellites
}

Ineffective management and cost overruns are plaguing an already troubled satellite system for tracking weather and climate, the US Government Accountability Office (GAO) reported to Congress on

17 June.

The National Polar-orbiting Operational Environmental Satellite System (NPOESS; illustrated right) was conceived in 1994 as a three-way project between the Department of Defense, the National Oceanic

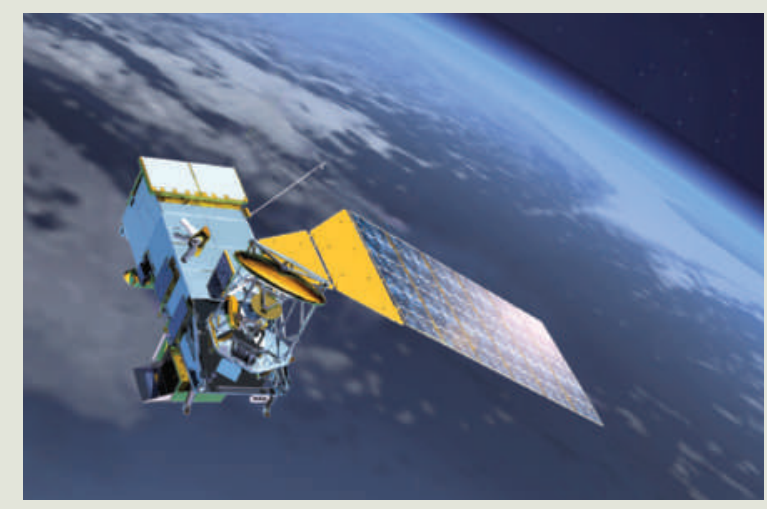
and Atmospheric Administration (NOAA) and NASA. "This tri-agency experiment has been an epic failure," says the GAO's David Powner.

In 2002, NPOESS was supposed to cost \$7 billion for six satellites, with the first to launch in 2009 (Nature 450, 782-785; 2007). Auditors now think that the current estimate $-\$ 14$ billion for four satellites beginning in 2014 - is at least $\$ 1$ billion off the mark. A separate report, conducted by an independent review team for NPOESS management, recommends that the White House appoint a top-level decision-maker, and suggests that NOAA should be made lead agency on the system.

minister Lisa Raitt appointed an expert panel to report by 30 November on how the country could ensure a stable long-term medical-isotope supply.

Three days earlier, US medical and nuclear non-proliferation groups wrote to Congress urging the United States to start its own domestic production of the isotopes, using low-enriched uranium.

\section{Climate projections taken to finest detail}

Stretching the predictive capabilities of climate models, researchers last week released an unprecedentedly detailed portrait of the impacts of long-term climate change on the United Kingdom.

The projections, produced by scientists at the Met Office and the Department for Environment, Food and Rural Affairs, run to 2080. They map climate effects to a resolution of 25 square kilometres, and resolve some weather patterns down to a scale of 5 square kilometres.

"Current climate science might support projections on a scale of a couple of thousand kilometres, but anything smaller than that is uncharted territory," says University of Oxford climatologist Myles Allen, who was part of a review committee commissioned to check the report's methodology.

Regional projections were also recently produced for the United States at a resolution of 25 square kilometres, at decadal timescales up to 2039 (see Nature doi:10.1038/news.2009.518; 2009).

For a longer version of this story, see http://tinyurl.com/projclim

\section{EU legislation increases clinical-trial workloads}

A review of the effects of the legislation governing clinical trials in the European Union has backed up some researchers' complaints about the regulations.

The 2001 European Clinical Trials Directive, which came into force from 2004, was intended to harmonize the rules governing clinical trials. But it has faced criticism from researchers who think it is overly complex and bureaucratic (see Nature doi:10.1038/news.2009.163; 2009).

Last week, the final report from the European Commission-funded project assessing the directive concluded that the measures increase workloads on trial sponsors and ethics committees, and delay the start of trials. The number of commercially-sponsored clinical trials in Europe increased by about $30 \%$ between 2003 and 2007, the report adds, whereas the number of non-commercially sponsored clinical trials remained constant. 